\title{
Cardiac Rehabilitation
}

National Cancer Institute

\section{Source}

National Cancer Institute. Cardiac Rehabilitation. NCI Thesaurus. Code C101234.

A medically supervised program to improve the health and well-being of people who have heart problems. This may include exercise training, education on heart healthy living, and/or counseling to reduce stress. (ACC) 